\title{
Quantitative and Qualitative Study of Phenolic Compounds Involved in Germination Inhibition of Wheat under Water Deficit
}

\author{
Abdelghani Chakhchar*, Salama Aissam, Cherkaoui El Modafar \\ Laboratory of Biotechnology Valorisation and Protection of Agro-Ressources, Faculty of Sciences and \\ Technology Gueliz, Cadi Ayyad University, Marrakech, Morocco \\ Email: "chakhchar.ckr@gmail.com
}

Received 24 June 2016; accepted 16 August 2016; published 19 August 2016

Copyright (C) 2016 by authors and Scientific Research Publishing Inc.

This work is licensed under the Creative Commons Attribution International License (CC BY). http://creativecommons.org/licenses/by/4.0/

(c) (i) Open Access

\begin{abstract}
In the aim to study the contribution of phenolic compounds in the inhibition of seeds germination of wheat (Triticum aestivum L.) under water deficit, we have forwarded quantitatively and qualitatively the change of the phenolic compounds levels in the seeds of two varieties (Achtar and Tigre) submitted to water stress induced by PEG-6000 during the germination stage. The results revealed significant differences between the stress intensity and duration and the polyphenol content. Some germination traits were significantly correlated with water stress and polyphenols in the both varieties studied. The polyphenol content in Tigre was much higher than those noted in Achtar. Analysis of phenolic extracts by HPLC showed the dominance of hydroxycinnamic derivatives $(97.2 \%$ and $94.5 \%$ in Tigre and Achtar, respectively). Regarding phenolic acid, the ferulic acid was the most dominant, and seemed to be related mainly to the inhibition of germination. Quantitatively, the Achtar variety was characterized by the presence of acid sinapic which was absent in Tigre variety. Furthermore, the water deficit appeared to stimulate the induction of salicylic acid accumulation in both varieties.
\end{abstract}

\section{Keywords}

Triticum aestivum L., Germination, Water Deficit, Polyphenols, Ferulic Acid

\footnotetext{
*Corresponding author.
}

How to cite this paper: Chakhchar, A., Aissam, S. and El Modafar, C. (2016) Quantitative and Qualitative Study of Phenolic Compounds Involved in Germination Inhibition of Wheat under Water Deficit. Technology and Investment, 7, 86-95. 


\section{Introduction}

Because of the global climate change and the increasing scarcity of water resources, wheat production is strongly influenced [1]. Wheat is the most produced cereal and the most consumed worldwide; it is also the most cultivated since it adapts to all types of land and climates. In Morocco, the water stress is a major limiting factor for the production of crops; since 65\% of the area reserved for cereals is located in arid and semi-arid Mediterranean-type environments (Regarding the Moroccan Ministry of Agriculture and Ficheries,

http://www.agriculture.gov.ma), which are characterized by irregular rainfall and high temperatures over a large part of the year. However, wheat contributes, on average, nearly $47 \%$ of the cereal gross value in Morocco [2]. In fact, the developing countries produce and utilize more than $80 \%$ of wheat they consume. Regarding to the Food and Agriculture Organization of the United Nations reports, the demand for wheat for human consumption in developing countries is expected to grow at 1.6\% each year in the period leading up to 2020 .

Water stress is one of the most important limitations of the development and the growth of plants because of the role of water in plant metabolism during germination. Indeed, the water deficit imposes itself as extrinsic factor that negatively influences the germination of seeds due to the essential and vital role of water in the induction of recovery of metabolic activity during germination process. In fact, this stage represents the critical and crucial step of plant growth. Many studies showed that the rate and speed of germination are reduced when the water potential of the medium decreases [3] [4].

The phenolic compounds in seeds were often implicated in the regulation of germination. They are known by their inhibitory effect. Given that the outer layers of mature seeds are rich in phenolic compounds, the content and nature of these compounds appear to be indexes for explain their involvement in the inhibition of seed germination. However, germination is generally improved when the levels of phenolic acids in seeds decreased during the natural evolution and following treatments applied to seeds [5].

The biological material for the present study consisted of seeds of Triticum aestivum L. So, the major aim of the study has been to investigate whether phenolic compounds are involved in the inhibition of wheat seed germination under water stress simulated with PEG-6000.

\section{Materials and Methods}

\subsection{Plant Material and Experimental Conditions}

Selected seeds of two Moroccan varieties of wheat (Triticuma estivum L.) Tigre and Achtar, kindly provided by the National Seed Marketing Company (SONACOS-Société Nationale de Commercialisation de Semences), were studied. The seeds were germinated in glass petri dishes (90 mm diameter), sterilized beforehand and not hermetically closed, containing the special medium. Each Petri dish contained 50 seeds (one replication). Our experiments were performed in control and PEG treatment conditions. We induced stressful conditions by different concentrations of PEG-6000: 20, 40, 60, 80 and 100 g/l PEG. Petri dishes were placed in incubator maintained at $25^{\circ} \mathrm{C} \pm 1^{\circ} \mathrm{C}$ and a photoperiod of $16: 8 \mathrm{~h}$ (light: dark). The experiment consisted of a randomized block design with six replications.

\subsection{Traits of Germination}

The number of germinated seeds was determined once a day until the percentage of germination was stable. For each treatment, we characterized the germination of two wheat varieties by four parameters: the maximum percentage of germination (MPG), the time to starting germination (TSG), the time to 50\% germination corresponding to $50 \%$ of total germinated seeds in the Petri dish (T50\% G) and the time to maximum germination (TMG).

\subsection{Total Polyphenols Content}

The finely ground powder was ground on ice in $80 \%$ methanol $(\mathrm{MeOH})$ and then sonicated for 10 minutes in ultrasonic bath (Elma, Germany) containing $700 \mathrm{ml}$ ultrapure water. The homogenate was centrifuged at 12,000 $\mathrm{x}$ $\mathrm{g}$ for $10 \mathrm{~min}$ at $4^{\circ} \mathrm{C}$. The concentration of polyphenols in the supernatants was determined with Folin-Ciocalteu reagent following the colorimetric method by adopting a differential assay in the presence/absence of 1\% (w/v) polyvinylpolypyrrolidine (PVPP) as described in [6]. Measurements were carried out in five replicates per 
treatment and calculations were based on a calibration curve obtained with gallic acid. The levels of polyphenols were expressed as micrograms of ferulic acid equivalents per gram of dry weight ( $\mu \mathrm{g} \mathrm{FAE} \mathrm{g}{ }^{-1} \mathrm{DW}$ ). There were 3 replicates per treatment (one plant per replicate).

\subsection{HPLC Analysis}

HPLC analysis of phenolic acids of wheat seeds extracts was performed with a Waters 600 system equipped with a photodiode array detector (Waters 2996) and a Waters 600 gradient pump. The column used as stationary phase was an Alltima C18 reversed-phase column $(250 \mathrm{~mm} \times 20 \mathrm{~mm}, 5 \mu \mathrm{m})$ with a C18 Guard-pak pre-column (Waters Assoc.). The mobile phase was composed of mixture of water-acetic acid (98: 2, v/v) (solvent A) and acetonitrile (solvent B). Phenolic acid separation was achieved using a 60-min linear solvent gradient at a flow rate of $1.0 \mathrm{~mL} / \mathrm{min}$. The solvent gradient was as follows: 0\% - 15\% B (10 min), 15\% - 20\% (10 min), 20\% - 30\% (10 min), 30\% - 40\% (5 min), 40\% - 55\% (5 min), 55\% - 80\% (5 min), 80\% - 100\% (2 min), 100\% (8 min) and $0 \%$ (5 min). After filtration through a syringe filter ( $25 \mathrm{~mm}$ GHP $0.45 \mu \mathrm{m}$, Acrodisc GHP), the injection volume was $20 \mu \mathrm{L}$. The different phenolic compounds were detected by absorption at the range of $240-400 \mathrm{~nm}$. Then, they were determined by comparing the retention times of known peaks of the following pure standards: galic, p-hydroxybenzoic, trans-cinnamic, caffeic, ferulic, sinapic and p-coumaric acids as well as vanillin and salicylic acid (Sigma Aldrich, USA). Concentrations of phenolic compounds were expressed as $\mu \mathrm{g}$ ferulic acid equivalent per gram of wheat, using the height and the area under peaks in quantitative calculations.

\subsection{Statistical Analysis}

Each data pointed the mean of three separate replicates, and mean values and standard deviations were calculated. Results were examined by the analysis of variance (ANOVA) in order to examine the effect of ecotype, time, watering regime and their interactions in each of the physiological and biochemical study variables. Means were compared using the Tukey's Post hoc test after checking the normality and the homoscedasticity of data. Pearson correlation analysis was done for some variables for each ecotype after checking the assumptions of parametric tests.

\section{Results}

\subsection{Traits of Germination}

The results of the variation of parameters related to the germination time showed significant differences depending on the variety $(\mathrm{P}<0.05)$ (Table 1$)$. The TSG was about 30 hours in Achtar variety and about 54 hours in Tigre variety. The T50\% G was about $37 \mathrm{~h}$ and $115 \mathrm{~h}$ in Achtar and Tigre varieties, respectively. Achtar variety was particularly less sensitive to different concentrations of PEG-6000, compared to Tigre variety. The TMG was 3 and 6 days in Achtar and Tigre varieties, respectively (Table 1). In Achtar variety, we recorded only $7 \%$ of the decrease in germination rate under the concentration of $100 \mathrm{~g} / \mathrm{L}$ PEG compared to the control (Figure 1). However, this rate started to decrease significantly at the lowest concentration tested 20 g/L PEG6000 in Tigre variety (Figure 2). Indeed, the germination capacity has decreased about $15 \%$ at $20-40 \mathrm{~g} / \mathrm{L}$ and $35 \%$ under the doses 60, 80 and 100 g/L PEG-6000, compared to the control.

\subsection{Total Polyphenols Content}

According the time taken to maximum germination for each variety (3 and 6 days for Achtar and Tigre, respectively), we followed the kinetic change of total polyphenols (Figure 3 and Figure 4). In fact, significant differences related to the factor "variety" were recorded. In control conditions, the total polyphenols contents decreased by approximately $18 \%$ and $23 \%$ in Tigre variety after six days and Achtar variety after three days, respectively (Figure 3 and Figure 4). The total polyphenols contents recorded in Tigre variety during germination, under water stress conditions, are higher than those recorded in Achtar in which we found the lowest level (366.67 $\mu \mathrm{g}$ ferulic acid equivalent/g) (Figure 3 and Figure 4). Thus, significant differences in total polyphenols contents were recorded under water stress conditions compared to control (Figure 3 and Figure 4). We also noted a significant decrease in total polyphenols contents taking into account the increased rate of germination in both varieties. Regarding water stress treatments, negative and significant correlations were recorded between 
the total polyphenols contents and the water stress duration $(r=0.91$ and $r=0.90$ in Tigre and Achtar, respectively) on the one hand and the other, between the total polyphenols contents and the germination capacity ( $\mathrm{r}=$ 0.90 and $\mathrm{r}=0.86$ in Tigre and Achtar, respectively).

\subsection{HPLC Phenolic Composition}

The quantitative and qualitative analysis of phenolic extracts of two wheat varieties studied was performed by HPLC. We chose phenolic extracts corresponding to the first, third and sixth day of the period of germination

Table 1. Effect of water stress induced by the PEG-6000 on germination parameters related to time: the time to starting germination (TSG), the time to $50 \%$ germination corresponding to $50 \%$ of total germinated seeds (T50\% G) and the time to maximum germination (TMG).

\begin{tabular}{|c|c|c|c|c|}
\hline \multirow{2}{*}{ PEG-6000 g/L } & \multirow{2}{*}{ Variety } & \multicolumn{3}{|c|}{ Germination parameters } \\
\hline & & TSG (h) & $\mathrm{T} 50 \% \mathrm{G}(\mathrm{h})$ & TMG (h) \\
\hline \multirow{2}{*}{0} & Achtar & 30 & 36 & 72 \\
\hline & Tigre & 50 & 100 & 144 \\
\hline \multirow{2}{*}{20} & Achtar & 30 & 36 & 72 \\
\hline & Tigre & 52 & 108 & 144 \\
\hline \multirow{2}{*}{40} & Achtar & 30 & 36 & 72 \\
\hline & Tigre & 53 & 108 & 144 \\
\hline \multirow{2}{*}{60} & Achtar & 32 & 36 & 72 \\
\hline & Tigre & 57 & 120 & 144 \\
\hline \multirow{2}{*}{80} & Achtar & 34 & 40 & 72 \\
\hline & Tigre & 58 & 128 & 144 \\
\hline \multirow{2}{*}{100} & Achtar & 34 & 40 & 72 \\
\hline & Tigre & 58 & 128 & 144 \\
\hline
\end{tabular}

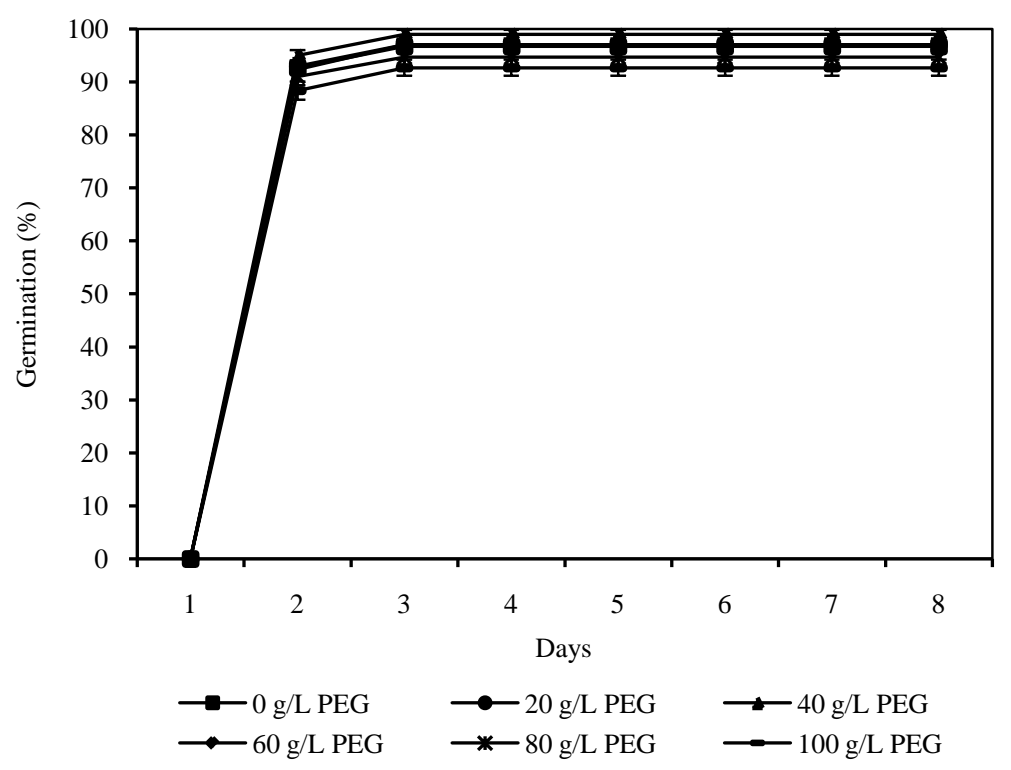

Figure 1. Effect of water stress induced by PEG-6000 on the germination rate in Achtar variety, during 8 days. Values represent the average of six independent counts \pm SD. 
for the Tigre variety, while for the Achtar variety, we studied the phenolic extracts relating the first and third day. Thus, we have considered only the treatments of water stress corresponding to concentrations: 60 and $100 \mathrm{~g} / \mathrm{L}$ of PEG-6000 by simulating moderate and severe water treatment, respectively. The HPLC-UV qualitative approach revealed two series of phenolic acids, including hydroxybenzoic and hydroxycinnamic derivatives (Table 2 and Table 3). Similarly, a qualitative difference was highlighted in terms of phenolic composition of seeds. Indeed, sinapic acid was detected only in phenolic extracts obtained from the seeds of Achtar variety (Table 2). According to the quantitative approach of the identified phenolic compounds, we distinguished that the acids derived from hydroxycinnamic acid are more abundant than those derived from the hydroxybenzoic acid, in both varieties. The fraction derived from hydroxycinnamic acid has averaged about $97.2 \%$ and $94.5 \%$ of the

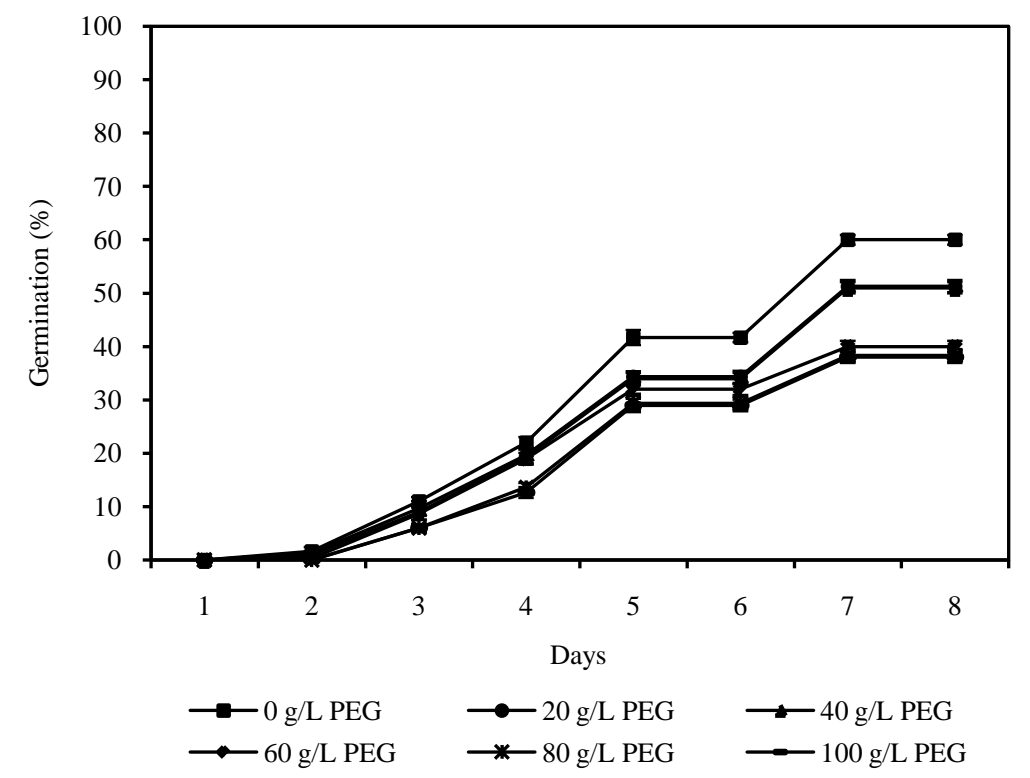

Figure 2. Effect of water stress induced by PEG-6000 on the germination rate in Tigre variety, during 8 days. Values represent the average of six independent counts $\pm \mathrm{SD}$ ).

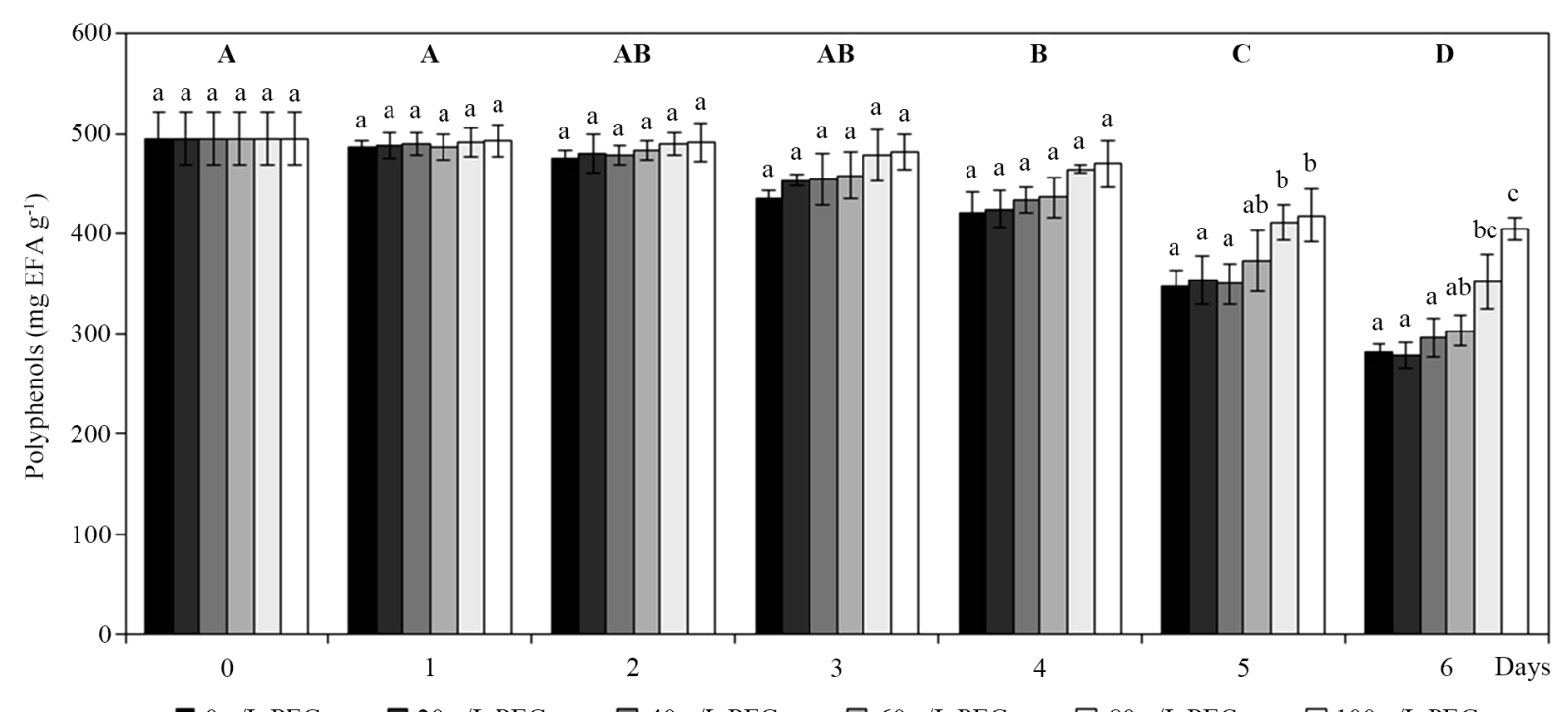

Figure 3. Effect of water stress induced by PEG-6000 on polyphenol contents in germinated seeds of Tigre variety, during 6 days of germination. Values (means of three replicates \pm SD) with distinct letters are significantly different at $5 \%$ (Tukey’s test). Upper-case letters indicate significant differences depending on time. 


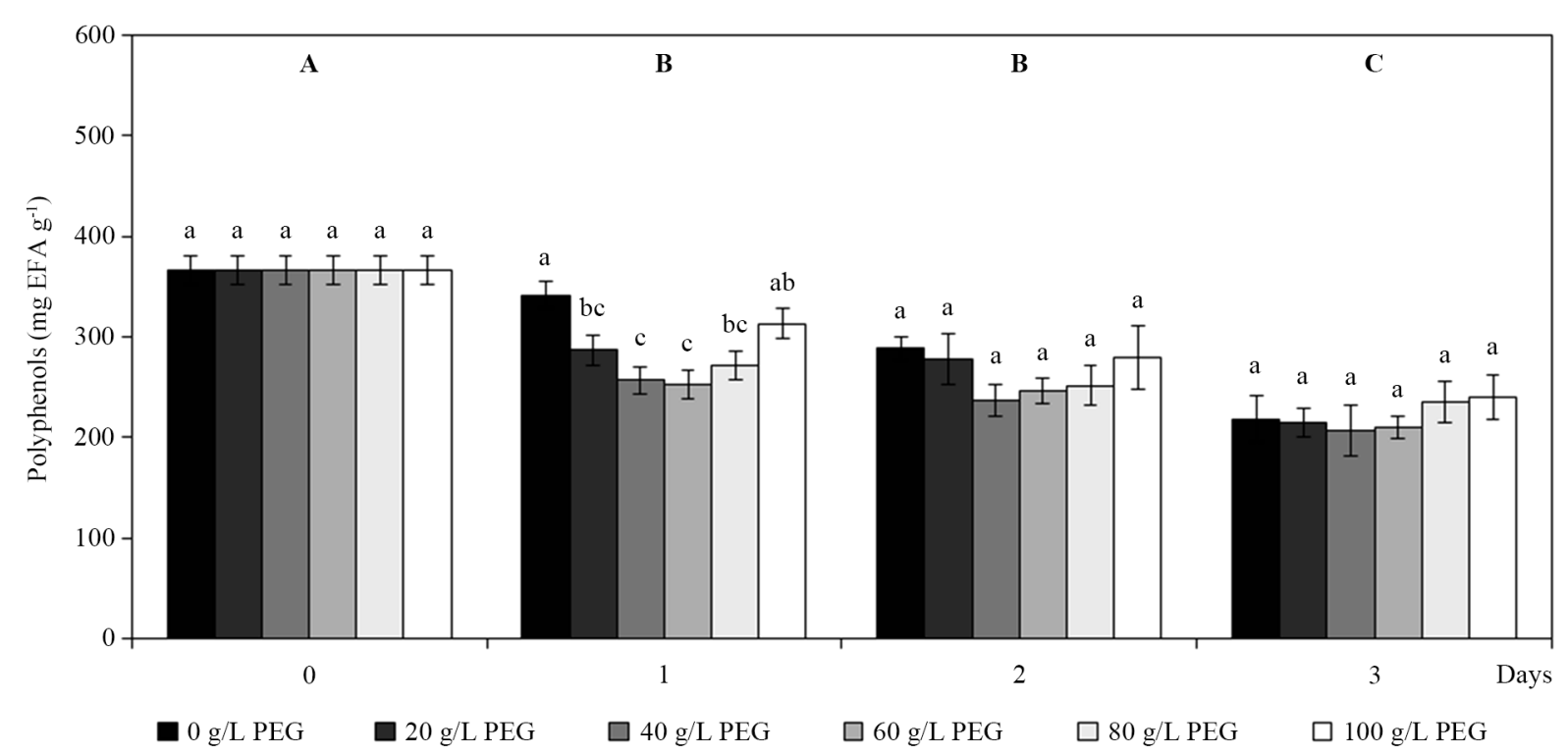

Figure 4. Effect of water stress induced by PEG-6000 on polyphenol contents in germinated seeds of Achtar variety, during 3 days of germination. Values (means of three replicates \pm SD) with distinct letters are significantly different at $5 \%$ (Tukey’s test). Upper-case letters indicate significant differences depending on time.

Table 2. Phenolic acids content ( $\mu \mathrm{g}$ EFA/g) in seeds extracts of Achtar variety under water stress treatments, during germination. (nd: No detected; PT: Total polyphenol).

\begin{tabular}{|c|c|c|c|c|c|c|c|c|}
\hline & \multicolumn{7}{|c|}{ Germinated seeds } & \multirow{3}{*}{$\begin{array}{c}\text { Seeds } \\
\text { control }\end{array}$} \\
\hline & \multicolumn{2}{|l|}{ Days } & \multicolumn{2}{|l|}{1} & \multicolumn{3}{|c|}{3} & \\
\hline & PEG (g/L) & 0 & 60 & 100 & 0 & 60 & 100 & \\
\hline \multirow{3}{*}{$\begin{array}{c}\text { Benzoic acid } \\
\text { derivatives }\end{array}$} & Gallic acid & 6.8 & 2.9 & 3.8 & 13.7 & 8.3 & 10.7 & 2.4 \\
\hline & OH-benzoic acid & 4.1 & 2.1 & 2.9 & 5.3 & 3.9 & 4.8 & 1.4 \\
\hline & Vanillin & 2.4 & 1.0 & 0.6 & 1.3 & 0.3 & 0.7 & 0.6 \\
\hline \multirow{8}{*}{$\begin{array}{c}\text { Cinnamic acid } \\
\text { derivatives }\end{array}$} & Caffeic acid & 4.7 & 4.9 & 4.4 & nd & nd & nd & 1.8 \\
\hline & Sinapic acid & 3.4 & 3.6 & 3.9 & 1.2 & 0.5 & 0.6 & 1.1 \\
\hline & p-coumaric acid & 1.2 & 1.0 & 1.3 & 0.9 & 0.9 & 1.1 & 1.5 \\
\hline & Salycilic acid & nd & nd & nd & 16.89 & 6.54 & 11.97 & nd \\
\hline & Cinnamic acid & 61.1 & 28.9 & 45.9 & 35.4 & 28.8 & 30.2 & 45.8 \\
\hline & Ferulic acid & 241.9 & 203.5 & 208.4 & 123.9 & 112.8 & 117.7 & 242.8 \\
\hline & PT (HPLC) & 325.7 & 248.2 & 271.2 & 198.5 & 162.1 & 177.7 & 297.3 \\
\hline & PT (FC) & 341.7 & 253.3 & 313.3 & 218.3 & 210.0 & 240.0 & 366.7 \\
\hline
\end{tabular}

phenolic composition identified in Tigre and Achtar varieties, respectively (Table 2 and Table 3). Knowing that ferulic and p-coumaric acid involved in the process of seed germination, we are particularly interested to follow their variation in both normal and stress conditions. Indeed, the two classes of phenolic acids have changed differently. In Achtar variety (Table 2), 44.04\% was the average estimate of the decrease in ferulic acid content under water stress conditions (60 and 100 g/L PEG). In Tigre variety (Table 3), we noted a significant decrease in ferulic acid, with increasing intensity of water stress, of about $6.3 \%, 2.7 \%$ and $0.8 \%$ during the $1^{\text {st }}$, $3^{\text {rd }}$ and $6^{\text {th }}$ day, respectively. The ratio of ferulic acid/other phenolic acids was about 2.7 and 3.5 in Achtar and Tigre varieties, respectively. 
Table 3. Phenolic acids content ( $\mu \mathrm{g}$ EFA/g) in seeds extracts of Tigre variety under water stress treatments, during germination. (nd: No detected; PT: Total polyphenol).

\begin{tabular}{|c|c|c|c|c|c|c|c|c|c|c|c|}
\hline & \multicolumn{10}{|c|}{ Germinated seeds } & \multirow{3}{*}{$\begin{array}{l}\text { Seeds } \\
\text { control }\end{array}$} \\
\hline & \multirow{2}{*}{$\begin{array}{c}\text { Days } \\
\text { PEG (g/L) }\end{array}$} & \multicolumn{3}{|c|}{1} & \multicolumn{3}{|c|}{3} & \multicolumn{3}{|c|}{6} & \\
\hline & & 0 & 60 & 100 & 0 & 60 & 100 & 0 & 60 & 100 & \\
\hline \multirow{3}{*}{$\begin{array}{c}\text { Benzoic acid } \\
\text { derivatives }\end{array}$} & Gallic acid & 3.9 & 1.5 & 2.1 & 9.0 & 6.2 & 8.9 & 5.3 & 6.7 & 4.5 & 3.3 \\
\hline & OH-benzoic acid & 4.3 & 1.5 & 4.6 & 4.4 & 2.6 & 2.9 & 2.5 & 2.1 & 2.7 & 7.2 \\
\hline & Vanillin & 1.8 & 4.3 & 1.8 & 0.8 & 0.7 & 0.7 & nd & nd & nd & 2.7 \\
\hline \multirow{8}{*}{$\begin{array}{c}\text { Cinnamic acid } \\
\text { derivatives }\end{array}$} & Caffeic acid & 5.2 & 6.2 & 6.2 & 5.5 & 3.1 & 3.9 & nd & nd & nd & 2.9 \\
\hline & Sinapic acid & nd & nd & nd & nd & nd & nd & nd & nd & nd & nd \\
\hline & p-coumaric acid & 1.5 & 1.8 & 2.5 & 1.1 & 1.2 & 1.8 & nd & nd & nd & 1.5 \\
\hline & Salycilic acid & nd & nd & nd & nd & nd & nd & 4.58 & 3.72 & 5.96 & nd \\
\hline & Cinnamic acid & 119.5 & 102.7 & 120.9 & 46.2 & 59.2 & 75.2 & 41.9 & 64.6 & 82.9 & 131.5 \\
\hline & Ferulic acid & 285.7 & 279.7 & 262.0 & 229.3 & 257.5 & 250.5 & 218.4 & 245.5 & 243.5 & 275.2 \\
\hline & PT (HPLC) & 421.9 & 397.7 & 400.0 & 296.3 & 330.5 & 343.8 & 272.7 & 322.6 & 339.6 & 424.2 \\
\hline & PT (FC) & 486.7 & 486.7 & 493.3 & 435.0 & 458.3 & 481.7 & 281.7 & 303.3 & 405.0 & 495.0 \\
\hline
\end{tabular}

According to the chromatograms obtained from the both varieties, we have highlighted a rich phenolic composition, mainly with phenolic acids. In fact, the phenolic acids identified in Tigre and Achtar varieties were: gallic acid, hydroxybenzoic acid, vanillin, caffeic acid, p-coumaric acid, cinnamic acid, ferulic acid and salicylic acid. However, the cinnamic acid was detected with high content after the acid ferulic, the most dominant in the phenolic composition of seeds (Table 2 and Table 3). Salicylic acid has been identified during the last day of the envisaged period of germination for each variety. Indeed, we detected it in both normal and stress conditions. The recorded contents of salicylic acid were particularly high as the concentration of PEG in the medium was increased. The salicylic acid contents recorded in Achtar variety were high compared to those in Tigre. Under water stress conditions (60 and $100 \mathrm{~g} / \mathrm{L}$ of PEG-6000), these contents averaged $4.84 \pm 1.58$ and $9.25 \pm 3.84 \mu \mathrm{g}$ FAE/g in Tigre and Achtar, respectively.

\section{Discussion}

\subsection{Traits of Germination}

Exposure of seeds of both wheat varieties, especially Tigre variety, to water stress induced by PEG-6000 was manifested by a significant decrease of the final percentage germination. Indeed, water stress seriously limits the rate of germination [3] [4]. However, the evolution of germination process revealed an increase in the time parameters in stressed seeds reflecting a real inhibition of germination. It seems that this inhibition would result particularly from the hydration difficulty of seed tissue, which affects the process of radicle elongation. Nevertheless, we found that a slight water deficit improved a little the germination in Achtar variety. Similar results have been reported for other species [7]-[9]. Furthermore, the Achtar variety showed a very high germination capacity compared to the Tigre variety. It appears that this variety can be of paramount importance in resistance to drought. At germination stage of wheat, differences depending on the variety, under water stress conditions, have been reported [3] [4] [9].

\subsection{Total Polyphenols Content}

Our results also showed changes of total polyphenols contents during the germination period, under water stress conditions. Thus, varietal differences, in terms of the variation of polyphenol contents, were recorded. Water stress as abiotic factor seriously influences the content of phenolic compounds in plant material [6]. The interaction 
between the intensity and duration of stress has decreased the germination rate. This decrease is often manifested by a low hydration of the parietal tissue, while the majority of the phenolic compounds in wheat are localized at the wall of seeds and this histological structure constitutes a pool of polyphenols [10] [11]. In the presence of PEG which induced an increase in water potential, the seeds have not got enough to ensure their imbibing to trigger the germination process. Therefore, a large phenolic fraction was not released due to the absence of certain tissue changes that accompany the germination of seeds (degradation reserves, structural modifications ...) especially in the chemical composition of the walls. The quantitative difference of the polyphenol contents depends mainly on the variety [12] [13].

\subsection{HPLC Phenolic Composition}

The majority of phenolic compounds that we have detected in the both varieties were phenolic acids and precisely hydroxycinnamic acid derivatives whose fraction of hydroxybenzoic acid derivatives was minor. Thus, the phenolic composition identified in the present work corroborates with other studies on wheat, with some differences (presence or absence of certain phenolic acid), according the variety effect [13]-[17]. Indeed, we found a qualitative difference regarding sinapic acid between the extracts of the both wheat varieties studied. In addition, we followed the change in content of p-coumaric and ferulic acid, which are the main phenolic acids involved in the inhibition of seed germination [18]. [19] reported significant interactions of abscisic acid (ABA) with phenolic acids, especially p-coumaric acids and ferulic acid on seed germination of lettuce. These phenolic compounds along with ABA had additive inhibitory effects on seed germination. Compared to control treatment, the slight decrease of phenolic acids in seeds subjected to water stress treatments (60 and $100 \mathrm{~g} / \mathrm{L} \mathrm{PEG)} \mathrm{appear}$ due to a low release of their bound forms. Indeed, we suggest that the presence of water in the environment can favor and accelerate their release of plant hormones that caused dormancy. Some authors reported an increase in the activity of several parietal hydrolases during germination, which promote the decrease of resistance imposed by the tissues surrounding the embryo [20] [21]. According to [22], ferulic acid can be linked to lignin and/or polysaccharides by ether or ester bonds at the cell wall. Similarly, p-coumaric acid may be esterified to the arabinoxylans but to a lesser degree as ferulic acid. This latter appears more often associated with lignin [23], but it would be also linked to the parietal glycoproteins. In light of our results, this parietal network, which requires very specific conditions to its hydrolysis, may play an inhibitory role of germination in the absence of a stimulator factor of this phenomenon. Moreover, the decrease detected in the phenolic acid contents, which are susceptible to be involved in the inhibition of germination, could be explained by the natural evolution of the germination process [5].

It is well known that salicylic acid plays an essential role in the induction of resistance genes as a long distance chemical signal responsible for systemic acquired resistance [24] [25]. This phenolic acid was detected late ( $3^{\text {rd }}$ and sixth day in Achtar and Tigre, respectively), which allows to suggesting that it was newly synthesized. Indeed, its biosynthesis would involve intermediaries such as cinnamic and benzoic acid in numerous species [26]-[28]. In this sense, we can suggest a metabolic relationship between the lower levels of certain phenolic acids identified in our extracts and the neo-synthesis of salicylic acid.

\section{Conclusion}

The quantitative and qualitative analysis of phenolic compounds in seeds of two varieties of wheat, under water stress conditions during germination, allowed to characterize the main phenolic acids, dominated by ferulic acid, in order to explain the involvement of these compounds in the germination inhibition. Varietal differences were noted for the contents of phenolic compounds and the germination parameters related to time, depending on the intensity and duration of stress. The induced water stress significantly affected MPG, TSG, T50\% G and TMG. In parallel, the polyphenol contents also varied significantly during the germination stage. The both varieties studied Achtar and Tiger were qualitatively distinguished by sinapic acid. However, a late induction of salicylic acid has been recorded in both varieties. Future researches on the role of phenolic compounds during wheat germination seem to be necessary to reduce their contents in order to enhance and accelerate germination.

\section{Acknowledgements}

The authors would like to thank entire team of "Laboratoire de Biotechnologie Valorisation et Protection des 
Agroressources”, Faculté des Sciences et Techniques Guéliz, Université Cadi Ayyad, Marrakech, Maroc.

\section{References}

[1] Shao, H.B., Liang, Z.S., Shao, M.A., Sun, S.M. and Hu, Z.M. (2005) Investigation on Dynamic Changes of Photosynthetic Characteristics of 10 Wheat (Triticum aestivum L.) Genotypes during Two Vegetative-Growth Stages at Water Deficits. Colloids and Surfaces B: Biointerfaces, 43, 221-227. http://dx.doi.org/10.1016/j.colsurfb.2005.05.005

[2] CIHEAM (2006) Centre International de Hautes Etudes Agronomiques Méditerranéennes. Rapport annuel de l'Agriculture Méditerranéenne.

[3] Qayyum, A., Razzaq, A., Ahmad, M. and Jenks, M.A. (2011) Water Stress Causes Differential Effects on Germination Indices, Total Soluble Sugar and Proline Content in Wheat (Triticum aestivum L.) Genotypes. African Journal of Biotechnology, 10, 14038-14045. http://dx.doi.org/10.5897/AJB11.2220

[4] Abdoli, M. and Saeidi, M. (2012) Effects of Water Deficiency Stress during Seed Growth on Yield and Its Components, Germination and Seedling Growth Parameters of Some Wheat Cultivars. International Journal of Agriculture and Crop Sciences, 4, 1110-1118.

[5] Weidner, S., Amarowicz, R., Karamac, M. and Fraczek, E. (2000) Changes in Endogenous Phenolic Acids during Development of Secale cereale Caryopses and after Dehydration Treatment of Unripe Rye Grains. Plant Physiology and Biochemistry, 38, 595-602. http://dx.doi.org/10.1016/S0981-9428(00)00774-9

[6] Chakhchar, A., Lamaoui, M., Wahbi, S., Ferradous, A., El Mousadik, A., Ibnsouda-Koraichi, S., Filali-Maltouf, A. and El Modafar, C. (2015) Leaf Water Status, Osmoregulation and Secondary Metabolism as a Model for Depicting Drought Tolerance in Argania spinosa. Acta Physiologiae Plantarum, 37, 1-16. http://dx.doi.org/10.1007/s11738-015-1833-8

[7] Pill, W.G. and Necker, A.D. (2001) The Effects of Seed Treatments on Germination and Establishment of Kentucky Bluegrass (Poa pratensis L.). Seed Science and Technology, 29, 65-72.

[8] Ashraf, M., Kausar, A. and Asraf, M.Y. (2003) Alleviation of salt stress in pearl millet (Pennisetum glaucum (L.) R. Br. through seed treatment. Agronomy, 23, 227-234. http://dx.doi.org/10.1051/agro:2002086

[9] Radhouane, L. (2008) Corrélation entre le stade germination et le stade adulte en presence de stress hydrique chez quelques écotypes autochtones tunisiens de mil (Pennisetum glaucum (L.) R. Br.). Comptes Rendus Biologies, 331, 623-630. http://dx.doi.org/10.1016/j.crvi.2008.05.001

[10] Antoine, C., Peyron, S., Mabille, F., Lapierre, C., Bouchet, B., Abecassis, J. and Rouau, X. (2003) Individual Contribution of Grain Outer Layers and Their Cell Wall Structure to the Mechanical Properties of Wheat Bran. Journal of Agricultural and Food Chemistry, 51, 2026-2033. http://dx.doi.org/10.1021/jf0261598

[11] Barron, C., Surget, A. and Rouau, X. (2007) Relative Amounts of Tissues in Mature Wheat (Triticum aestivum L.) Grain and Their Carbohydrate and Phenolic Acid Composition. Journal of Cereal Science, 45, 88-96. http://dx.doi.org/10.1016/j.jcs.2006.07.004

[12] Beaugrand, J., Croner, D., Debeire, P. and Chabbert, B. (2004) Arabinoxylan and Hydroxycinnamate Content of Wheat Bran in Relation to Endoxylanase Susceptibility. Journal of Cereal Science, 40, 223-230. http://dx.doi.org/10.1016/j.jcs.2004.05.003

[13] Verma, B., Hucl, P. and Chibbar, R.N. (2009) Phenolic Acid Composition and Antioxidant Capacity of Acid and Alkali Hydrolysed Wheat Bran Fractions. Food Chemistry, 116, 947-954. http://dx.doi.org/10.1016/j.foodchem.2009.03.060

[14] Li, W., Shan, F., Sun, S.C., Corke, H. and Beta, T. (2005) Free Radical Scavenging Properties and Phenolic Content of Chinese Black-Grained Wheat. Journal of Agricultural and Food Chemistry, 53, 8533-8536. http://dx.doi.org/10.1021/jf051634y

[15] Kim, K.H., Tsao, R., Yang, R. and Cui, S.W. (2006) Phenolic Acid Profiles and Antioxidant Activities of Wheat Bran Extracts and the Effect of Hydrolysis Conditions. Food Chemistry, 95, 466-473. http://dx.doi.org/10.1016/j.foodchem.2005.01.032

[16] Hu, C., Cai, Y.Z., Li, W., Corke, H. and Kitts, D.D. (2007) Anthocyanin Characterization and Bioactivity Assessment of a Dark Blue Grained Wheat (Triticum aestivum L. cv. Hedong Wumai) Extract. Food Chemistry, 104, 955-961. http://dx.doi.org/10.1016/j.foodchem.2006.12.064

[17] Verma, B., Hucl, P. and Chibbar, R.N. (2008) Phenolic Content and Antioxidant Properties of Bran in 51 Varieties of Wheat. Cereal Chemistry, 85, 544-549. http://dx.doi.org/10.1094/CCHEM-85-4-0544

[18] Gross, D. and Parthier, B. (1994) Novel Natural Substances Acting in Plant Growth Regulation. Journal of Plant Growth Regulation, 13, 93-114. http://dx.doi.org/10.1007/BF00210953

[19] Li, H.H., Inoue, M., Nishimura, H., Hasegawa, K., Mizutani, J. and Tsuzuki, E. (1993) Interactions of Trans-Cinnamic Acid, Its Related Phenolic Allelochemicals, and Abscisic Acid in Seedling Growth and Seed Germination of Lettuce. 
Journal of Chemical Ecology, 19, 1775-1787. http://dx.doi.org/10.1007/BF00982307

[20] Bewley, D.J. (1997) Seed Germination and Dormancy. The Plant Cell, 9, 1055-1066. http://dx.doi.org/10.1105/tpc.9.7.1055

[21] Welbaum, G.E., Bradford, K.J., Kyu-Ock, Y. and Oluoch, M.O. (1998) Biophysical, Physiological and Biochemical Processes Regulating Seed Germination. Seed Science Research, 8, 161-172. http://dx.doi.org/10.1017/S0960258500004074

[22] Max, B., Torrado, A.M., Moldes, A.B., Converti, A. and Dominguez, J.M. (2009) Ferulic Acid and p-Coumaric Acid Solubilization by Alkaline Hydrolysis of the Solid Residue Obtained after Acid Prehydrolysis of Vine Shoot Prunings: Effect of the Hydroxide and pH. Biochemical Engineering Journal, 43, 129-134. http://dx.doi.org/10.1016/j.bej.2008.09.015

[23] Jung, H.G. (1989) Forage Lignins and Their Effects on Fiber Digestibility. Agronomy Journal, 81, 33-38. http://dx.doi.org/10.2134/agronj1989.00021962008100010006x

[24] Klessig, D.F., Durner, J., Shah, J. and Yang, Y. (1998) Salicylic Acid-Mediated Signal Transduction in Plant Disease Resistance. In: Romeo, J.T., Downum K.R. and Verporte, R., Eds., Phytochemical Signals and Plant-Microbe Interactions, Vol. 32, Plenum Press, New York, 119-137. http://dx.doi.org/10.1007/978-1-4615-5329-8_7

[25] Smith, H.B. (2000) Signal Transduction in Systemic Acquired Resistance. The Plant Cell, 12, 179-181. http://dx.doi.org/10.1105/tpc.12.2.179

[26] Coquoz, J.L., Buchala, A. and Metraux, J.P. (1998) The Biosynthesis of Salicylic Acid in Potato Plants. Plant Physiology, 117, 1095-1101. http://dx.doi.org/10.1104/pp.117.3.1095

[27] Chong, J., Pierrel, M.A., Atanassova, R., Werck-Reichhart, D., Fritig, B. and Saindrenan, P. (2001) Free and Conjugated Benzoic Acid in Tobacco Plants and Cell Cultures. Induced Accumulation upon Elicitation of Defense Responses and Role as Salicylic Acid Precursors. Plant Physiology, 125, 318-328. http://dx.doi.org/10.1104/pp.125.1.318

[28] Lim, E.K., Doucet, C.J., Li, Y., Elias, L., Worrall, D., Spencer, S.P., Ross, J. and Bowles, D.J. (2002) The Activity of Arabidopsis Glycosyltransferases toward Salicylic Acid, 4-Hydroxybenzoic Acid, and Other Benzoates. The Journal of Biological Chemistry, 277, 586-592. http://dx.doi.org/10.1074/jbc.M109287200

\section{Submit or recommend next manuscript to SCIRP and we will provide best service for you:}

Accepting pre-submission inquiries through Email, Facebook, LinkedIn, Twitter, etc.

A wide selection of journals (inclusive of 9 subjects, more than 200 journals)

Providing 24-hour high-quality service

User-friendly online submission system

Fair and swift peer-review system

Efficient typesetting and proofreading procedure

Display of the result of downloads and visits, as well as the number of cited articles

Maximum dissemination of your research work

Submit your manuscript at: http://papersubmission.scirp.org/ 